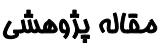

\section{اثرات ضد درد محلول كلوكز انسولين - يتاسيم در انفاركتوس حاد قلبى}

\author{
مريمر هاشميان'، ، عليرضا وكيلى'، آرش اكابرى
}

IRCT:138804302210N1

$$
\begin{aligned}
& \text { 'يز شكى عمومى، مركز تحقيقات بالينى، دانشخاه علوم يزشكى سبزوار، سبزوار، ايران }
\end{aligned}
$$

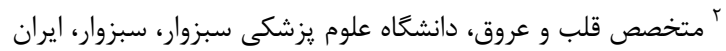

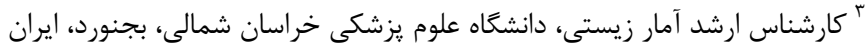

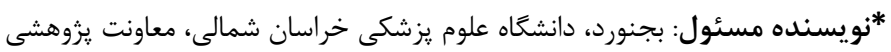

$$
\begin{aligned}
& \text { يست الكترونيك:Arashdata@yahoo.com }
\end{aligned}
$$

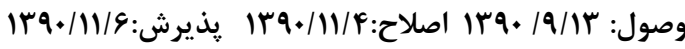

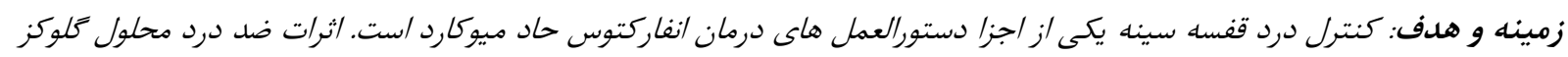

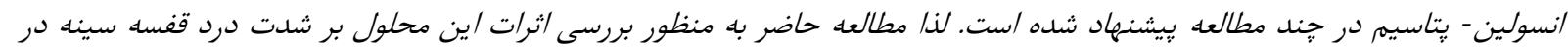

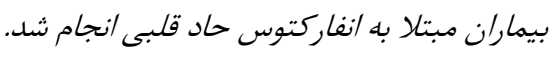

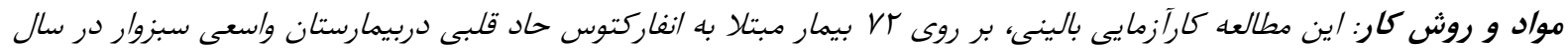

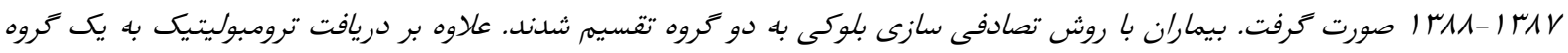

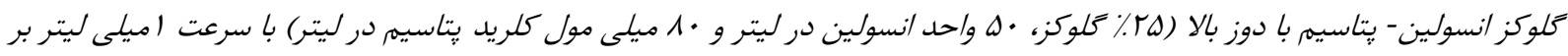

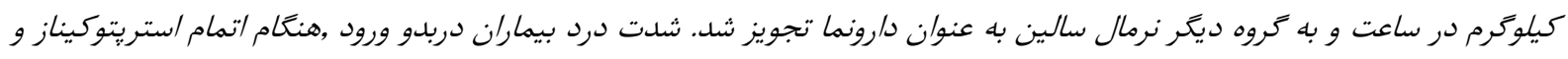

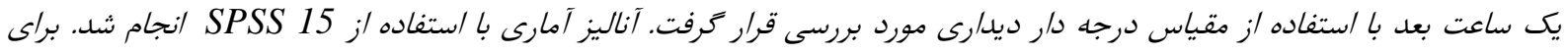

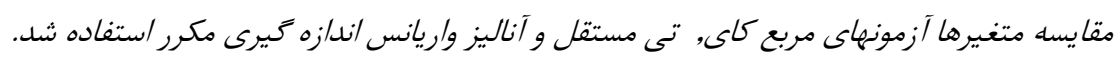

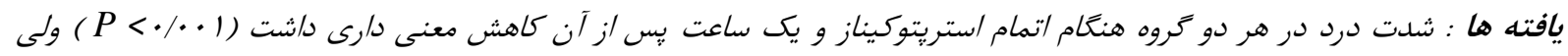

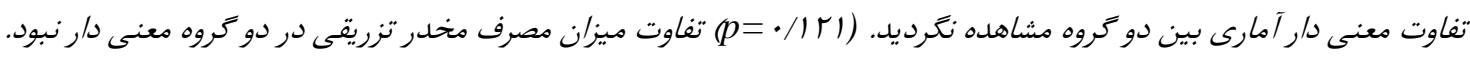

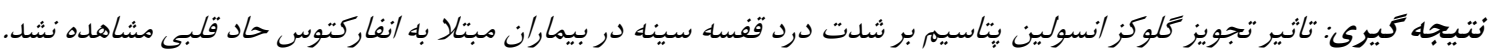

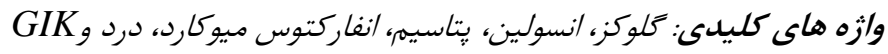

كليه اين دستورالعملها از نيترو كليسيرين، دستورالعمل هاى درمانى انفاركتوس ميو كارد بوده است.

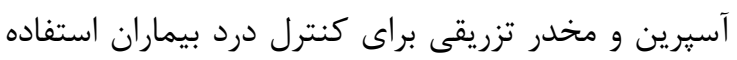

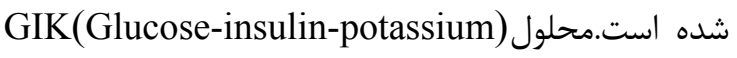
متشكل از كلوكز، انسولين، يتاسيم و آب اولين بار در دها

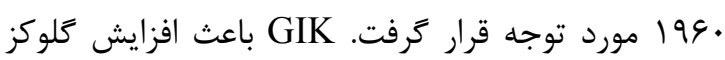

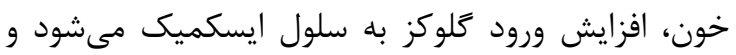
سلول ميوكارد اسيدهاى خرب آزاد را كمتر مورد استفاده

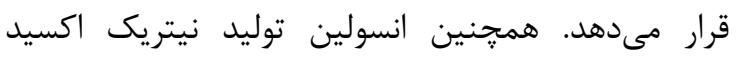

\section{مقدمه}

درد و درمان آن، در اولين دسته از نيازهاى اساسى بشر

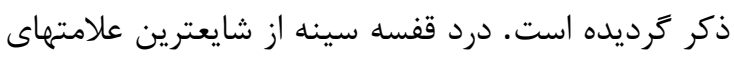

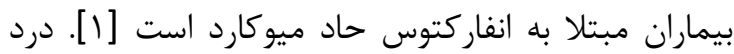

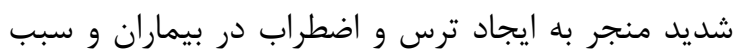

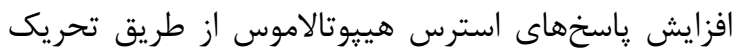

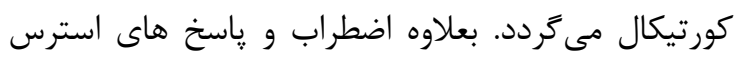

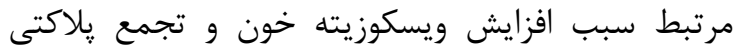

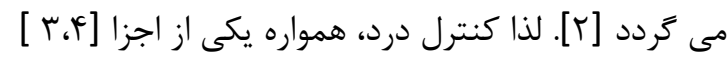


گرفته و اگر كنترا انديكاسيونى وجود نداشت وارد مطالعه شدن [r-Y]]. معيارهاى اصلى خروج از مطالعه عبارتند از: بيماران تحت درمان با كلوكوكورتيكوئيد و عفونت سيستميك، هييوتانسيون، كراتينين>r ب، بيماران مبتلا به به بهوبه نارسايى احتقانى قلب و همو كلوبين كمتر از 11 و و ترديد در مورد تشخيص و علت غير قلبى درد قفسه سينه. يس از بررسى معيارهاى ورود و خروج و در صورت برقرارى معيار و كسب رضايت نامه كتبى از بيمار (مورد

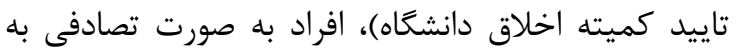
دو گروه مداخله و شاهد تخصيص يافتند. جهت تصادفى

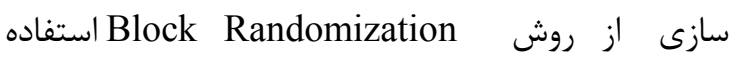
نموديم. در اين ميان بيمار و مشاور آمار و نيز يرسشگر اطلاع نداشتند كه بيمار جزو گروه مداخله است يا شاهد (سه سو كور). تصادفى كردن و تجويز GIK فقط در مورد

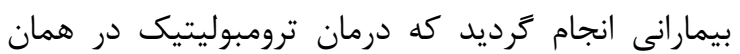

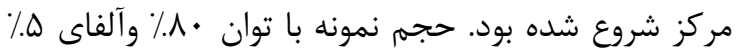

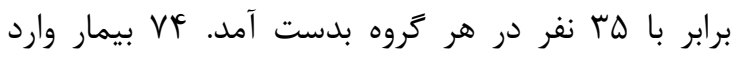

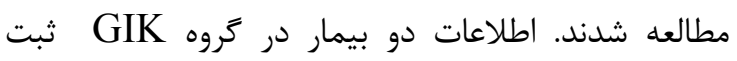
نشده بود و نهايتاً VY نفر مورد بررسى قرار گرفته اند.

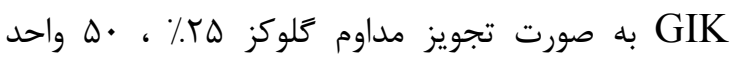

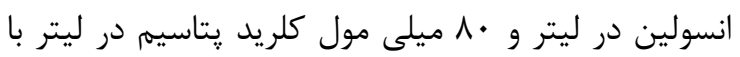
سرعت يك سى سى بر كيلوگرم در ساعت به بيماران داده شد. محلول فوق توسط كمك يروهشگر تهيه و همزمان با

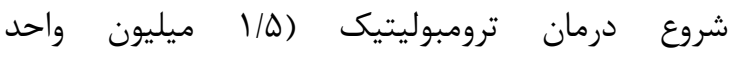

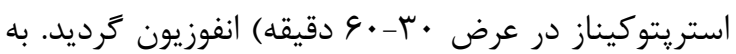
كروه شاهد يك ليتر سرم نرمال سالين با سرعت •9 سى سى در ساعت به عنوان دارو نما، علاوه بر درمان

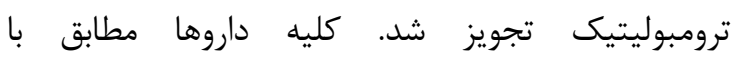
دستورالعمل درمان انفاركتوس ميوكارد مربوط به انجمن قلب امريكا (ACC / AHA guideline ) تجويز شد [ب] مئو مخدر تزريقى بر حسب ميزان درد بيمار و با تجويز يزشك تجويز شد. در هر بيمار سطح آنزيمهاى كراتينين كيناز

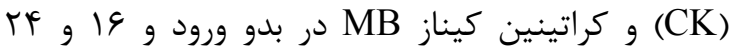
ساعت بعد اندازه گيرى شد. در همه بيماران غلظت

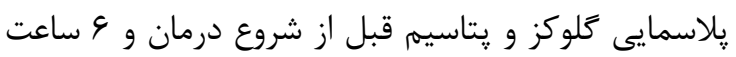
يس از آن اندازه خيرى شد.
توسط اندوتليوم را تحريك مى كند [ه] و اثرات گشاد كنندگى عروقى دارد. مطالعات قبلى اكثرا بر روى رو رلى اثراتGIK بر مرى و مير انجام شده است و نتايج متناقضى نيز داشتهاند. مطالعه متا آناليز كه در سال مرال 199V توسط فت اردوبادى انجام شده، تعداد 9 مطالعه كار آزمايى بالينى را از 1999-1999 بررسى كرده است.

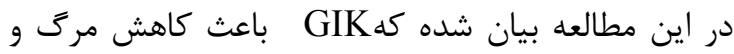

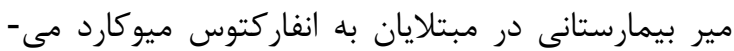

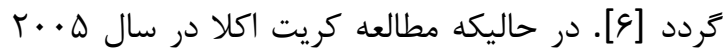
تجويز GIK را بر مرى و مير سى روزه و وقايع وخيم ترن

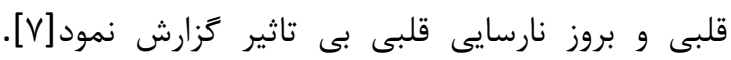

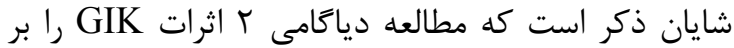
بيماران مبتلا به ديابت مورد بررسى قرار داد و باز هم اثر

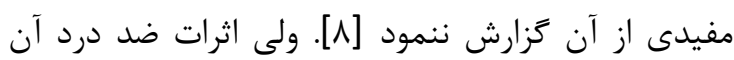
تنها در קند مطالعه محدود بررسى شده است. مطالعه ایى ان كه توسط فال سليمان و همكاران براى بررسى اثرات GIK بر سير بسترى و حوادث داخل بيمارستانى انجام

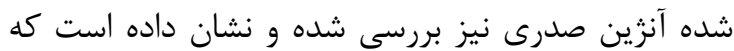
تجويز GIK باعث كاهش اندك درد قلبى بيماران مبتلا به

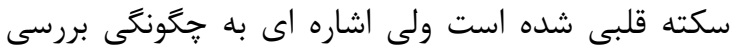

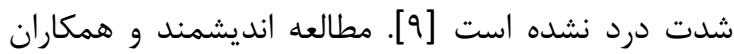
نيز فقط بيماران مبتلا به آنزين صدرى نايايدار را مورد

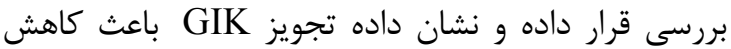

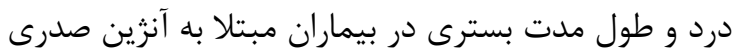

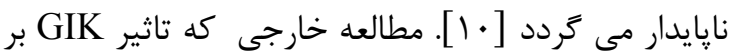
درد بيماران را مورد بررسى قرار داده باشد يافت نشد. لذا

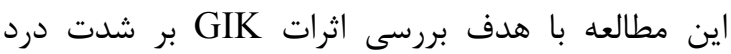

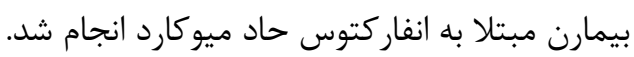

\section{روش كار}

مطالعه كارآزمايى بالينى حاضر در مهر ماه I IVV آغاز و تا

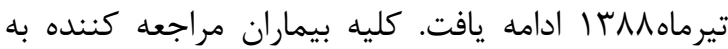

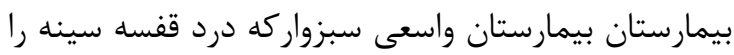
به مدت حداقل ·r دقيقه داشتند و در حالى كه از شروع علائم بيمار كمتر از ז ا ساعت كذشته بود ECG گرفته شد. كليه كسانى كه همزمان با درد در ECG قطعه بيش از 1 ميلى متر در حداقل r اشتقاق مجاور بالا رفته بـ دمرده بود، از نظر كنترانديكاسيون استريتوكيناز مورد بررسى قرار 


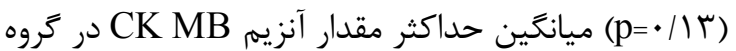
مورد 119

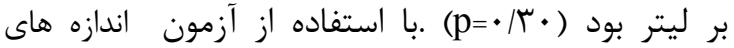
مكرر، تفاوت بين دو گروه از نظر سطح سرمى آنزيم هاى

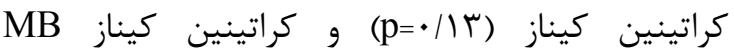

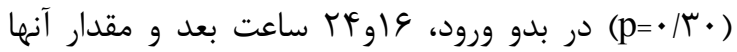
معنى دار نبود. عوارض سرم GIK در بيماران به صورت دو مورد فلبيت شديد (צ•/عدر صد) مشاهده شد. موردى از هيبر كالمى مشاهده نشد. سطح كلوكز خون در بدو ورود در گروه مورد

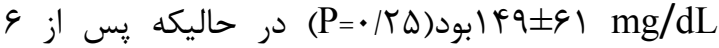

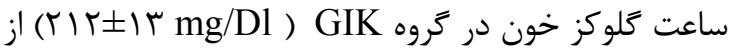

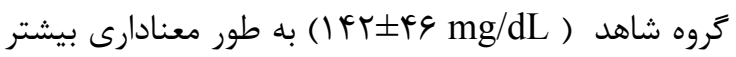

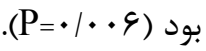

بحث نتايج مطالعه نشان داد شدت درد در هر دو گروه به طور

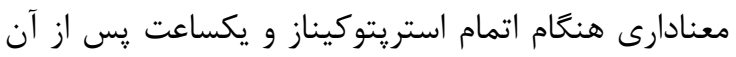
كاهش يافت ولى تفاوت معنى دار آمارى بين دو گروها مشاهده نشد. همجنين از نظر ميزان مصرف مخدر تزريقى

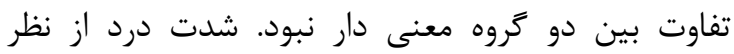

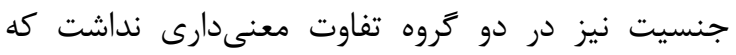
مطابق با يافته هاى مطالعات قبلى است [1/11]]. در مطالعه اى كه توسط انديشمند و همكاران بر روى بيماران مبتلا به آنزين صدرى نايايدار انجام شده نشان داده تجويز - ماند GIK

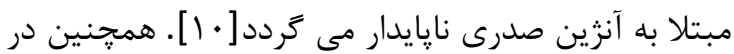
مطالعه اى كه توسط فال سليمان و همكارانش برروى

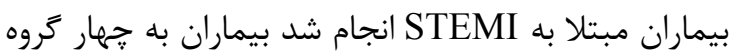
درمان با استريتوكيناز به تنهايى، GIK به تنهايى، درمان

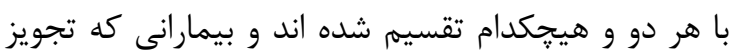

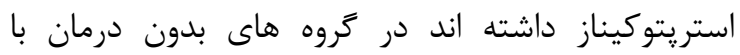
استريتوكيناز قرار گرفته اند ونتيجه گرفته اند، منجر به كاهش اندك در درد قفسه سينه شده است [9]

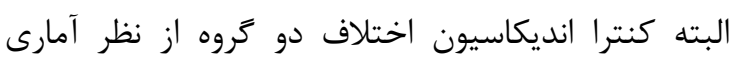
نزديك به معنى دار بوده است. بنابراين مى توان نتيجه

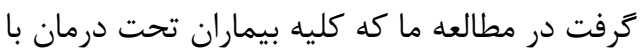

براى تعيين شدت درد از مقياس درجهدار عددى (Numeric Rating Scale , NRS) ترتيب كه از بيماران خواسته شد كه شدت درد خود را با اعداد صفر تا ده مشخص كنند،كه صفر به معناى بى دردى و ده به معناى شديدترين درد قابل تصور مىباشد. شدت درد بيماران در بدو ورود، هنغام اتمام استريتوكيناز و يك ساعت يس از اتمام استر يتوكيناز

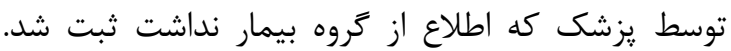
آناليز آمارى با استفاده از 15 SPSS انجام شد. متغيرهاى ليمار ييوسته به صورت (ميانخين ثلانحراف معيار) بيان شده اند. براى مقايسه متغيرها از آزمونهاى مربع كاى, تئى مستقل و آناليز واريانس اندازه گيرى مكرر استفاده شده است. ه• • • $\alpha=$ (مخدرهاى تزريقى مورد استفاده شامل مورفين سولفات و

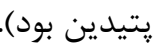

يافته ها

تفاوت قابل ملاحظه اى بين دو گروه از نظر متغيرهاى دموگرافيك و يايه (سن، جنس، مصرف سيعار، يرفشارى

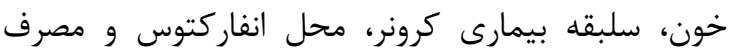
مواد مخدر) و مصرف مخدر قبل از مراجعه وجود نداشت و

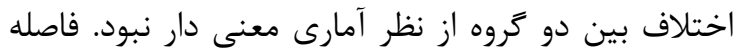
زمانى شروع درد قفسه سينه تا تجويز استريتوكيناز

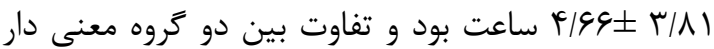
نبود (19=• p=. شدت درد، دربدو ورود، يس إز اتمام استريتوكيناز و يك ساعت پيس از اتمام استريتوكيناز سنجيده شد. نتايج مطالعه نشان داد: از نظر كنترل شدت درد تفاوت بين دو گروه معنى دار نيست (نمودار (). شدت درد در هر دو گروه هنگام اتمام

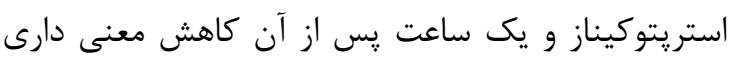
داشت ( ( I P P ) ولى تفاوت معنى دار آمارى بين دو

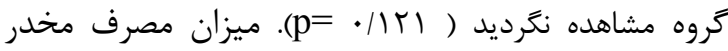

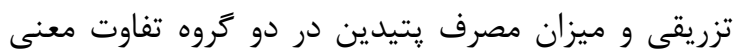
دار نداشت. شدت درد از نظر جنسيت نيز در دو گروه تفاوت معنى دارى نداشت بود. ميانگين حداكثر مقدار

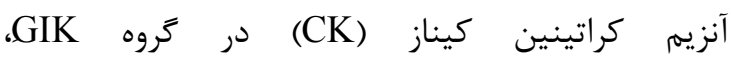
هو

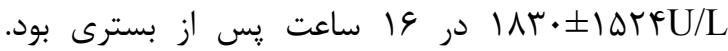




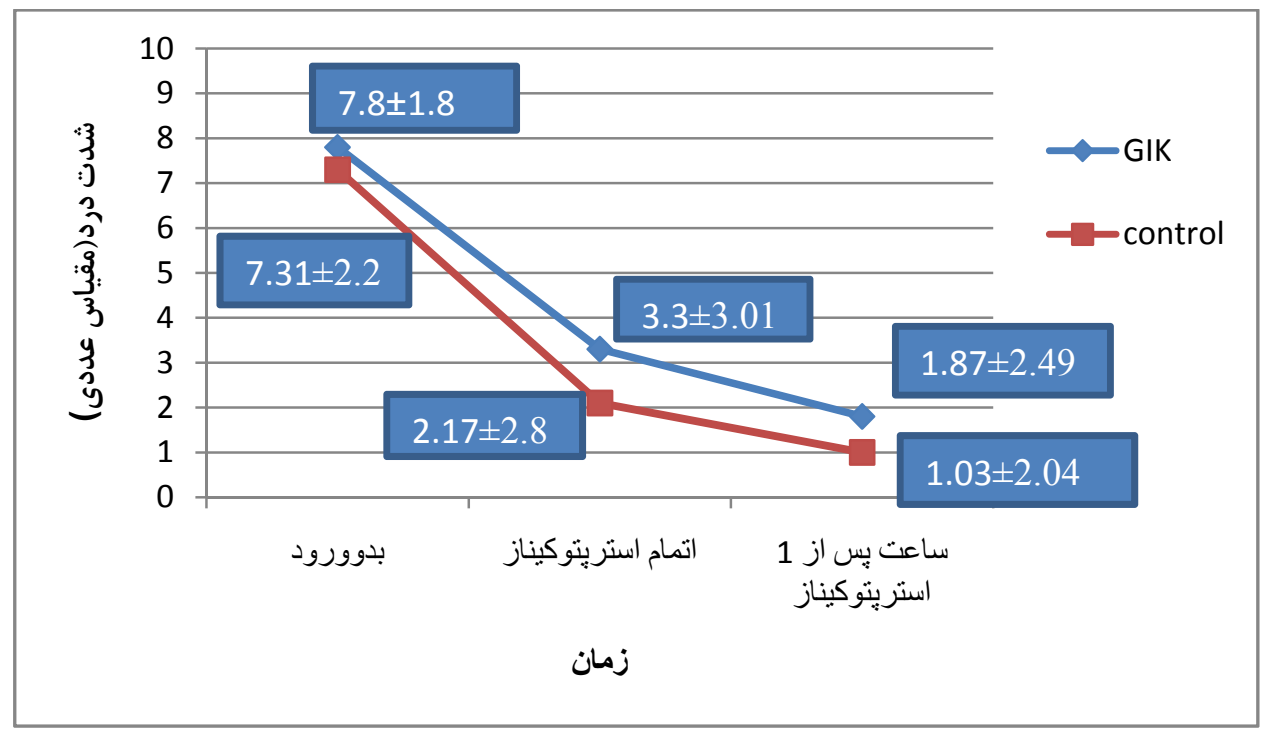

نمودار ا:نمودار شدت درد دربابيمارشركت كننده در مطالعه كارازمايى بالينى اثر كلوكز انسولين يتاسيم درانفاركتوس ميوكارد

استريتوكيناز وجود ندارد يا كنترا انديكاسيونى وجود دارد

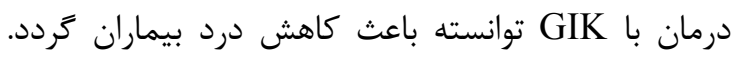

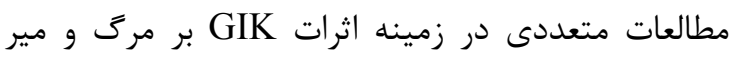
انجام شده است. متا آناليز انجام شده توسط فت اوردودين اتربادى

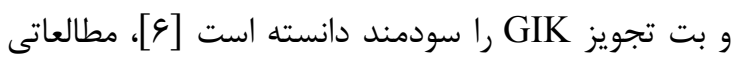

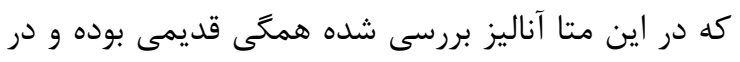

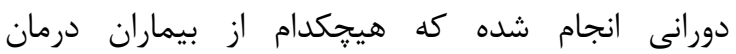
ترومبوليتيك دريافت نكرده اند. در مطالعه-DIAGAMI, داندان

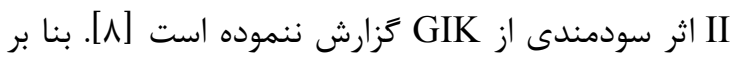
اين به نظر مى رسد در شرايطى كه برقرارى مجدد جريان خون به ميزان كافى توسط درمان ترومبوليتيك صورت

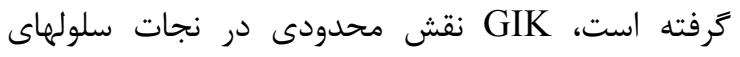

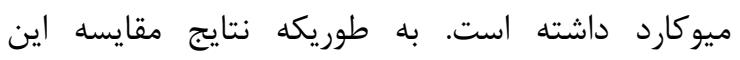
مطالعات نيز با مقايسه مطالعات بررسى اثرات ضد دات درد درد

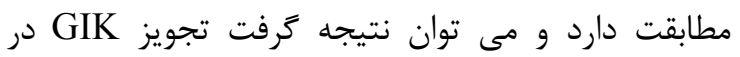

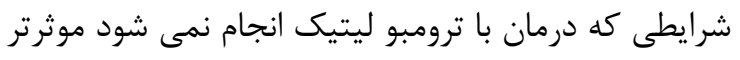

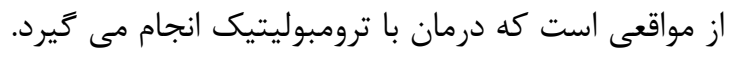

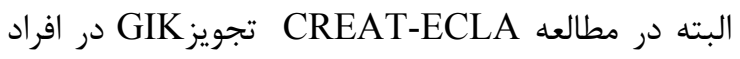
دريافت كننده ترومبوليتيك و كسانى كه ترومبوليتيك دريك

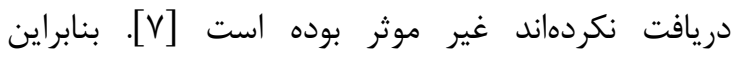
مىتوان كفت تجويز GIK حداقل در كنترل درد در افراد
استريتوكيناز قرار گرفته اند استريتوكيناز باعث حل لخته و كاهش درد بيماران شده است و GIK موثر نبوده است در حاليكه در مطالعه انديشمند كه جمعيت مورد مطالعه دونه

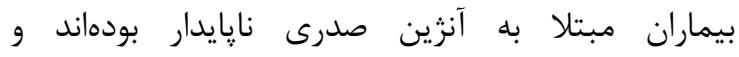

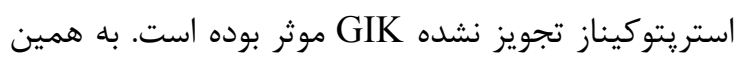
علت است كه در مطالعه فال سليمان كه برخى از بيماران

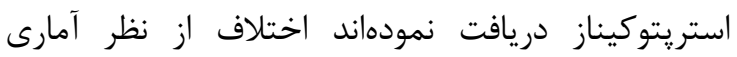

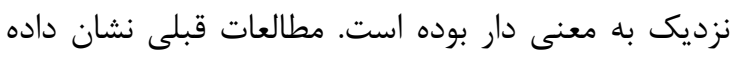

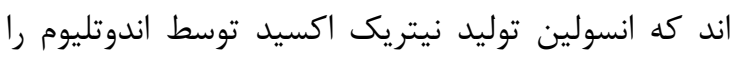

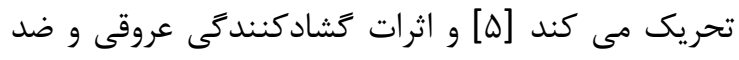

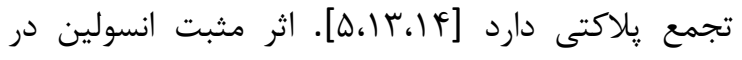

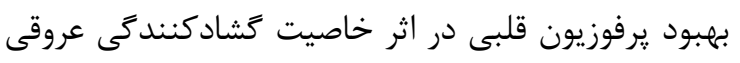

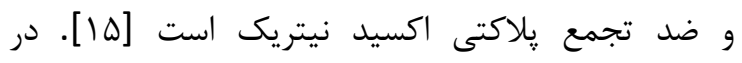

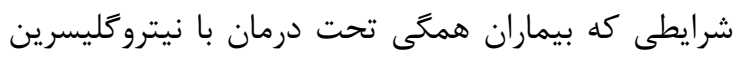

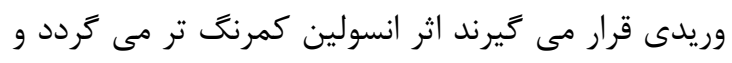

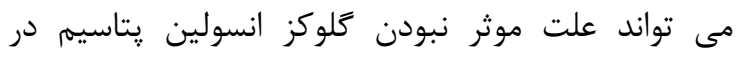

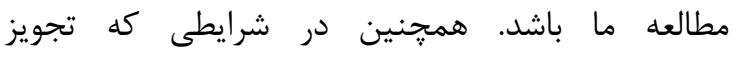

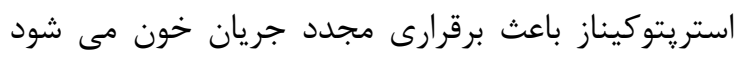

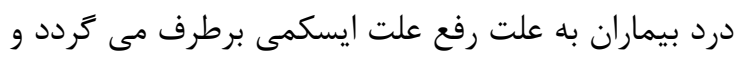

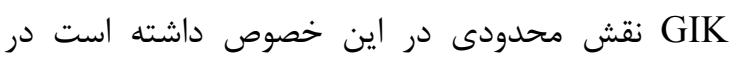

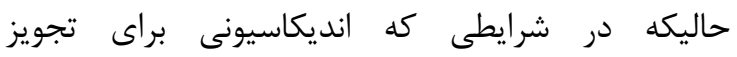




\section{دريافت كننده ترومبوليتيك بى تاثير است. جادهرى نيز}

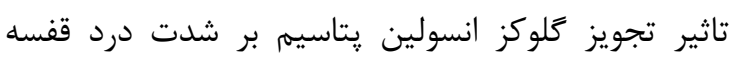

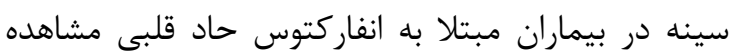

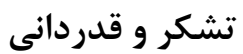

بدين وسيله از معاونت محترم يزوهشى دانشى دانشاه علوم يزشكى سبزوار كه هزينه انجام اين طرح تحقيقاتى را مان متقبل شدند و سركار خانم لادن نجار، عضو محترم هيات علمى دانشكاه علوم يزشكى سبزوار، كليه يرستاران بخش

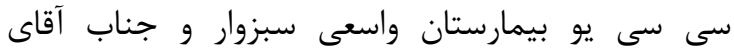
آذرشب و سركار خانم يزمان و كليه كسانى كه ما را در

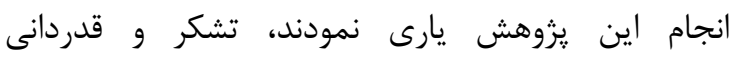
مى كر دد.

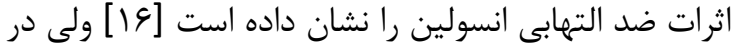

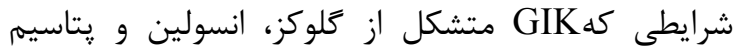

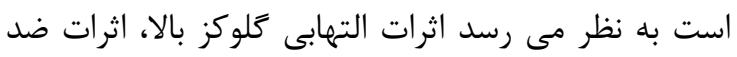
التهابى انسولين را تحت يوشش قرار دهد. در مطالعه ما متوسط سطح كلوكز يس از 4 ساعت در گروه GIK به

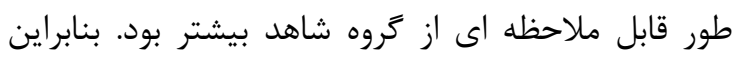

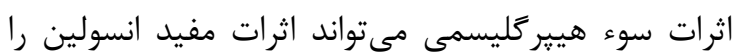
بيوشاند و باعث بى اثر شدن GIK كردد. از جمله

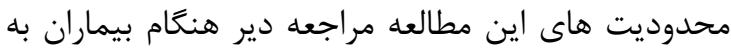

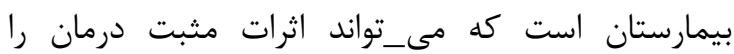

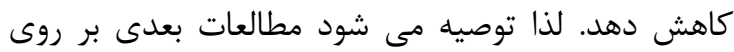

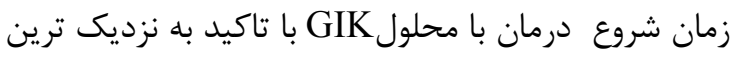
زمان بعد از شروع درد تمركز نمايند. 


\section{References}

1. Peter Libby ROB, Dougias L Mann,Dougias P Zipes, ed, Braunwald's Heart Disease, Philadelphia: Saunders 2008.

2. Nasiunpur SH, Pain,Nashr Tabib, TEHRAN 2004. $1^{\text {st }}$ edition.[persion]

3. Kushner FG, Hand M, Smith SC, Jr , King SB, 3rd, Anderson JL, Antman EM, "et al", 2009 Focused Updates: ACC/AHA Guidelines for the Management of Patients With ST-Elevation Myocardial Infarction (updating the 2004 Guideline and 2007 Focused Update) and ACC/AHA/SCAI Guidelines on Percutaneous Coronary Intervention (updating the 2005 Guideline and 2007 Focused Update): a report of the American College of Cardiology Foundation/American Heart Association Task Force on Practice Guidelines, Circulation 2009 Dec 1;120(22):2271-306.

4. Van de Werf F, Bax J, Betriu A, Blomstrom-Lundqvist C, Crea F, Falk V, "et al", Management of acute myocardial infarction in patients presenting with persistent ST-segment elevation: the Task Force on the Management of ST-Segment Elevation Acute Myocardial Infarction of the European Society of Cardiology. European heart journal 2008 Dec;29(23):2909-45.

5. Cardillo C, Nambi SS, Kilcoyne CM, Choucair WK, Katz A, Quon MJ, "et al", Insulin stimulates both endothelin and nitric oxide activity in the human forearm, Circulation 1999 Aug 24;100(8):820-

6. Fath-Ordoubadi F, Beatt KJ, Glucose-insulin-potassium therapy for treatment of acute myocardial infarction: an overview of randomized placebo-controlled trials, Circulation 1997 Aug 19;96(4):1152-

7. Mehta SR, Yusuf S, Diaz R, Zhu J, Pais P, Xavier D," et al”, Effect of glucose-insulin-potassium infusion on mortality in patients with acute ST-segment elevation myocardial infarction: the CREATE-ECLA randomized controlled trial, Jama 2005 Jan 26;293(4):437-46.

8. Malmberg K, Ryden L, Wedel H, Birkeland K, Bootsma A, Dickstein K," et al",Intense metabolic control by means of insulin in patients with diabetes mellitus and acute myocardial infarction (DIGAMI 2): effects on mortality and morbidity,European heart journal 2005 Apr;26(7):650-61.

9. Fal soleyman $\mathrm{h}$,dehghani m.,shakeri m.t.,valizadeh g, Effect of gik serum on hospital course of patients with st elevation myocardial infarction, Medical journal of mashhad university of medical sciences fall 2006; 49(93):261-266[Persian]

10.Andishmand a ,sadr bafghi s.m ,motefaker mostafa,azimi m.r.,azimi a, effect of glucose- insulin potassium (gik) solution onshort termprognosis of unstable angina, Journal of shahid Sadoughi University of medical sciences and health services fall 2007; 15(3):14-19[Persian]

11.Sabzevari $\mathrm{s}^{*}$,mohammad alizadeh $\mathrm{s}$,bagherian ,mirzaei fatemeh, comparison of signs and symptoms of myocardial infarction and unstable angina in male and female hospitalized patients in coronary care units of kerman medical university hospital 2004-2005, Journal of mazandaran university of medical sciences april-may 2007; 17(57):42-49[Persian]

12. Ashton K.C, How men and women with heart disease seek care: The delay experience, Prog, Cardiovascular Nurs 1999 spring; 14(2): 53-60.

13. Steinberg HO, Brechtel G, Johnson A, Fineberg N, Baron AD, Insulin mediated skeletal muscle vasodilatation is nitric oxide dependent: a novel action of insulin to increase nitric oxide release,J Clin Invest 1994;94:1172-1179.

14. Trovati M, Massacco P, Mattiello L, Mularoni E, Cavalot F, Anfossi G, Insulin increases guanosine-3=, $5=$-cyclic monophosphate in human platelets: a mechanism involved in the insulin antiaggregating effect,Diabetes 1994;43:1015-1019.

15. Pinelli A, Triyulzio S, Tomasoni L, Bertolini B, Brenna S, Bonacina E.Cardiac necrosis markers associated with low nitric oxide levels in the plasma of rabbits after treatment with vasopressin: protective effects of nitroglycerin administration, Pharmacol Res 2002;45:427-434.

16. Chaudhuri A, Janicke D, Wilson MF, Tripathy D, Garg R, Bandyopadhyay A, "et al", Antiinflammatory and profibrinolytic effect of insulin in acute ST-segment-elevation myocardial infarction, Circulation 2004 Feb 24;109(7):849-54. 
Original Article

\title{
Evaluation of analgesic effect of glucose - insulin - potassium in acute myocardial infarction
}

\author{
IRCT:138804302210N1 \\ Hashemian $M^{1}$,Vakili $A R^{1}$,Akaberi $A^{* 2}$
}

${ }^{1} \mathrm{MD}$, Sabzevar University of Medical Sciences, Sabzevar,Iran

${ }^{2}$ M.Sc of Biostatistic, North Khorasan University of Medical Sciences, Bojnurd, Iran

*CorrespondingAuthor: Norh Khorasan University of Medical Sciences

E mail: Arashdata@yahoo.com

Submitted: 2012 Jan 3

Revised: 2012 Jan 24

Accepted: 2012 Jan 26

\begin{abstract}
Background \& Objectives: chest pain control is one of the most important components of guidelines for acute myocardial infarction. An analgesic effect of glucose, insulin potassium solution has been suggested in a few studies. Hence this study was performed to evaluate the effect of this solution on the intensity of chest pain in patients with myocardial infarction.

Materials \& Methods: This randomized clinical trial enrolled 72 patients who had myocardial infarction that was treated with $25 \%$ glucose, 50 unit of soluble insulin per liter, and 80 mille mol of potassium chloride per liter at $1 \mathrm{ml} / \mathrm{kg} /$ hour (case group) or normal saline (control group) as adjunct to thrombolytic therapy. We evaluated pain intensity at baseline, after receiving thrombolytic therapy and 1 hour later, in both groups by a Numeric Rating Scale. Statistical analysis was performed using SPSS 15. Variables were compared using independent $t$ tests and repeated measure ANOVA or chi-square test. Results: In both groups pain intensity after receiving streptokinase and an hour later dropped, but there was no significant differences between two groups $(P=0.121)$. Difference between intravenous drug consumption in the two groups was not significant $(P=0.93)$.

Conclusion: The administration of potassium, glucose, insulin has no effect on chest pain in patients with myocardial infarction. Key words: glucose, insulin, potassium, myocardial infarction, pain, GIK
\end{abstract}

